\title{
A Neural Circuit Analysis of Visual Recognition Memory: Role of Perirhinal, Medial, and Lateral Entorhinal Cortex
}

\author{
Raymond P. Kesner, ${ }^{2}$ Ajay Ravindranathan, ${ }^{1}$ Pamela Jackson, ${ }^{3}$ Ryan Giles, \\ and Andrea A. Chiba ${ }^{4}$ \\ Departments of Psychology and ${ }^{1}$ Anatomy, University of Utah, Salt Lake City, Utah 84112, USA
}

\begin{abstract}
Using a continuous recognition memory procedure for visual object information, we sequentially presented rats with eight novel objects and four repeated objects (chosen from the 8). These were selected from 120 different three-dimensional objects of varying sizes, shapes, textures, and degree of brightness. Repeated objects had lags ranging from 0 to 4 (from 0 to 4 different objects between the first and repeated presentation). An object was presented on one side of a long table divided in half by an opaque Plexiglas guillotine door, and the latency between opening the door and the rat moving the object was measured. The first presentation of an object resulted in reinforcement, but repeated presentations did not result in a reinforcement. After completion of acquisition training (significantly longer latencies for repeated presentation compared with the first presentation of an object), rats received lesions of the perirhinal, medial, or lateral entorhinal cortex or served as sham operated controls. On the basis of postsurgery testing and additional tests, the results indicated that rats with perirhinal cortex lesions had a sustained impairment in performing the task. There were no sustained deficits with medial or lateral entorhinal cortex lesions. The data suggest that recognition memory for visual object information is mediated primarily by the perirhinal cortex but not by the medial or lateral entorhinal cortex.
\end{abstract}

In recent years, excellent progress has been made in identifying the neural circuit that supports short-term memory for visual object information as measured in visual object recognition paradigms. In monkeys, cortical visual processing of object recognition is assumed to be organized as a set of hierarchically connected cortical regions, including the peristriate cortex, posterior inferior temporal cortex $\left(\mathrm{TE}_{\mathrm{O}}\right)$, inferior temporal cortex $\left(\mathrm{TE}_{3}, \mathrm{TE}_{\mathrm{a}}, \mathrm{TE}_{\mathrm{m}}\right)$, anterior temporal cortex $\left(\mathrm{TE}_{1}, \mathrm{TE}_{2}\right)$, perirhinal cortex, and entorhinal cortex. All these areas have been shown to play some role in memory for visual object information (Ungerleider and Mishkin 1982; Horel et al. 1987; Martin-Elkins et al. 1989; Gaffan and Murray 1992; Meunier et al. 1993; Eacott et al. 1994).

The major emphasis in recent years has been on determining the role of the rhinal cortex (perirhinal and entorhinal cortex) in memory for visual object information. The rhinal cortex in monkeys is essential for mediation of visual object recognition memory. This conclusion is based on the

${ }^{2}$ Corresponding author.

E-MAIL rpkesner@behsci.utah.edu; FAX (801) 581-5841. Present addresses: ${ }^{3}$ Department of Psychology, Radford University, Radford, VA 24142, USA; ${ }^{4}$ Department of Cognitive Science, University of California San Diego, La Jolla, CA 92093, USA.

Article and publication are at www.learnmem.org/cgi/doi/ 10.1101/lm.29401. observation that rhinal cortex lesions produce a severe deficit in visual recognition memory on a delayed match or nonmatch-to-sample task (Horel et al. 1987; Zola-Morgan et al. 1989; Gaffan and Murray 1992; Meunier et al. 1993; Eacott et al. 1994; Buffalo et al. 1999). Because perirhinal cortex lesions are sufficient to produce this visual object recognition memory deficit (Meunier et al. 1993; Gaffan 1994; Buckley et al. 1997) and entorhinal cortex lesions only produce transient effects (Leonard et al. 1995), it appears that the perirhinal cortex is essential for visual object recognition memory. On the basis of anatomical evidence, a similar hierarchical organization has been uncovered in the rat between primary visual cortex and medial and lateral extrastriate visual cortex, temporal $\left(\mathrm{TE}_{2}\right)$ cortex, and perirhinal cortex (Deacon et al. 1983; Miller and Vogt 1984; Coogan and Burkhalter 1990; Sanderson et al. 1991; Vaudana et al. 1991). The medial extrastriate visual cortex has been identified as an important substrate in mediating memory for visual object information (Kesner et al. 1993). Another important area might be the $\mathrm{TE}_{2}$ area of the temporal cortex and perirhinal cortex, because Kolb et al. (1994), Davis and McDaniel (1993), and Mumby and Pinel (1994) have shown that lesions of these areas produce a deficit in a visual matching-to-sample task. Previous research in which nonmatching-to-sample procedures were used has indicated that lesions of the perirhinal cortex in

LEARNING \& MEMORY 8:87-95 @ 2001 by Cold Spring Harbor Laboratory Press ISSN1072-0502/01 \$5.00

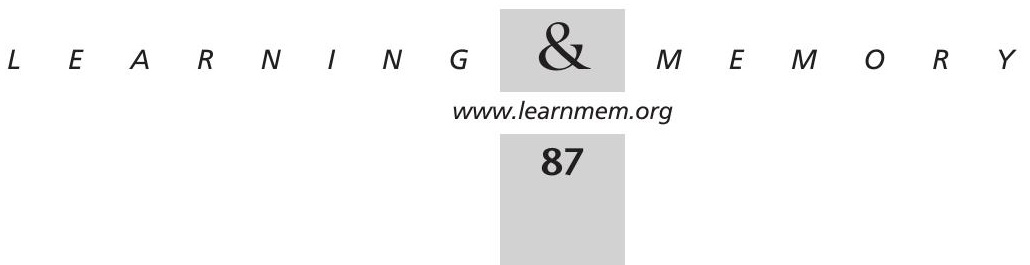


the rat also disrupt visual recognition memory (Kolb et al. 1994; Mumby and Pinel 1994; Ennaceur et al. 1996; Aggleton et al. 1997; Barnes et al. 2000). In most of the abovementioned studies, perirhinal cortex lesion in rats included, in addition to the perirhinal cortex, the lateral entorhinal cortex. It was therefore deemed important to reexamine the role of the perirhinal cortex by comparing the effects of lesions of the perirhinal cortex with lesions of the medial entorhinal and lateral entorhinal by using a continuous recognition memory paradigm. Medial and lateral entorhinal cortex were made separately based on their anatomical connections with the hippocampus and other brain regions (Witter et al. 1989) and based on the observation that the contribution of the lateral and medial entorhinal cortex to
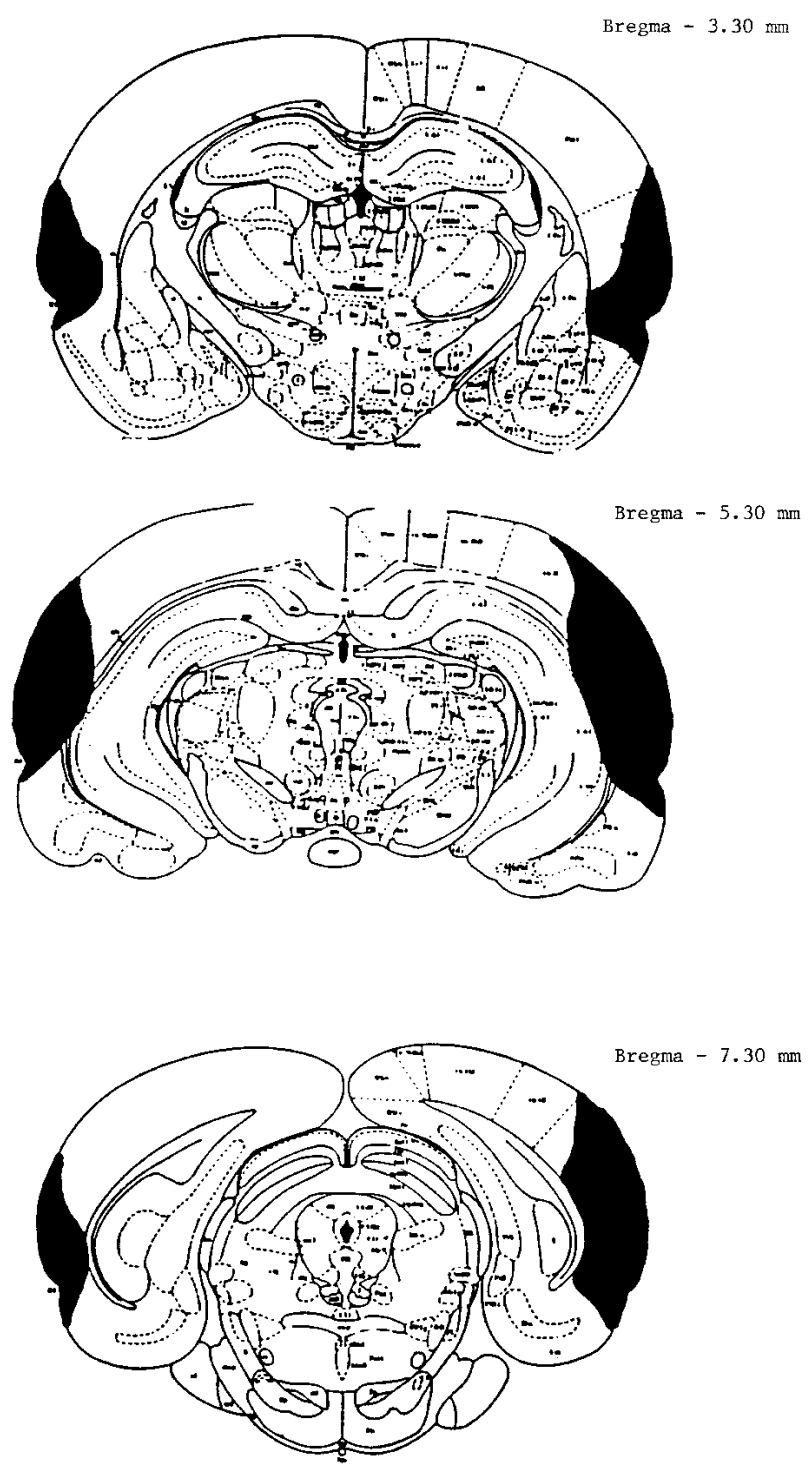

Figure 1 A schematic drawing of a representative lesion of the perirhinal cortex. Rat brain sections were taken from Paxinos and Watson (1986).
Table I. Performance Index Data for Rats with Perirhinal Cortex Lesions

\begin{tabular}{lccc}
\hline $\begin{array}{l}\text { Percent } \\
\text { damage to } \\
\text { perirhinal } \\
\text { cortex }\end{array}$ & $\begin{array}{c}\text { Percent damage } \\
\text { to anterior } \\
\text { perirhinal cortex }\end{array}$ & $\begin{array}{c}\text { Percent } \\
\text { damage to } \\
\text { postrhinal } \\
\text { cortex }\end{array}$ & $\begin{array}{c}\text { Performance } \\
\text { index* }\end{array}$ \\
\hline 54.8 & 51.4 & 65.9 & .861 \\
55.3 & 54.9 & 56.8 & .677 \\
34.3 & 26.9 & 27.3 & .561 \\
47.5 & 44.3 & 58.0 & .398 \\
54.2 & 54.2 & 47.3 & .325 \\
18.3 & 19.3 & 15.0 & .315 \\
67.3 & 71.1 & 55.3 & .281 \\
43.3 & 48.6 & 26.0 & .273 \\
\hline
\end{tabular}

Percent damage to perirhinal cortex, anterior perirhinal cortex, and posterior perirhinal cortex (postrhinal cortex), and performance on the continuous-recognition memory task for rats with perirhinal cortex lesions.

*The higher the score, the worse the performance.

recognition memory for spatial information can be dissociated (Kesner and Giles 1998). The continuous recognition memory task involves sequential presentation of 12 threedimensional objects, within one session, all of which have been selected from a set of 120 objects. From the 12 objects, 8 were novel and 4 of the 8 were presented twice. Repeated objects had lags ranging from 0 to 4 (from 0 to 4 different objects were presented between the first and the repeated presentation). Rats were reinforced for approaching the novel object, but they were not reinforced for approaching a repetition. Rats learn this task quickly and show significantly longer latencies to approach and move the repeated compared with the novel objects. Furthermore, the shorter the lag, the greater the latency difference. In previous research using this task, it has been shown that visual object continuous recognition memory is not affected by hippocampal lesions (Jackson-Smith et al. 1993).

\section{RESULTS}

\section{Histology}

Histological analysis of the perirhinal cortex lesions (Fig. 1) revealed that there was extensive bilateral damage to perirhinal cortex extending $\sim 4.5 \mathrm{~mm}$ in the anterior-posterior plane. There was also damage to $\mathrm{TE}_{2}$ cortex in half of the subjects but no damage to entorhinal cortex. In all subjects, there was damage to $\mathrm{TE}_{1}$ and $\mathrm{TE}_{3}$ cortex. In three of the eight subjects, there was damage to the parietal cortex. Further quantitative analysis revealed that damage to the anterior perirhinal cortex ranged from $19.3 \%$ to $71.1 \%$, whereas damage to the postrhinal cortex ranged from $15.0 \%$ to $65.9 \%$ (see Table 1). According to Burwell et al. (1995), the postrhinal cortex includes the perirhinal cortex from -7.5 to 9.0 posterior to bregma, according to the Paxinos and Watson (1986) atlas.

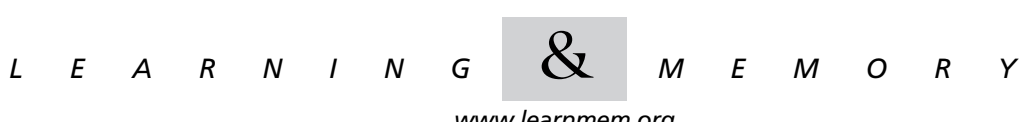


Histological analysis of the lateral entorhinal cortex lesions (Fig. 2) revealed primary damage to the lateral entorhinal cortex (a range of $53.3 \%-82.2 \%$ ) as well as significant
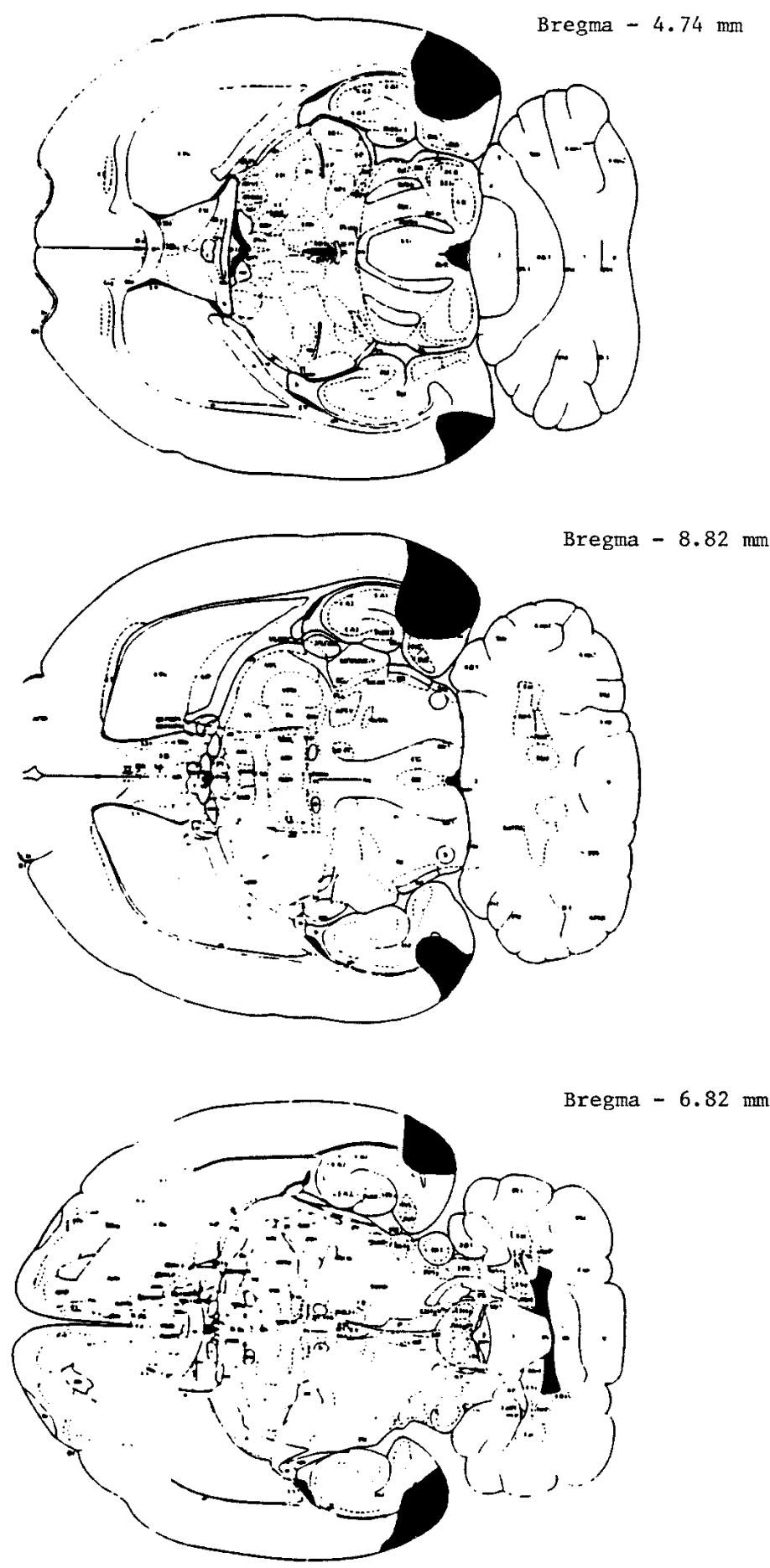

Figure 2 A schematic drawing of a representative lesion of the lateral entorhinal cortex. Rat brain sections were taken from Paxinos and Watson (1986). damage to the postrhinal cortex (a range of 32.5\%-67.8\%), but no damage to the anterior rhinal cortex and only mild damage to the ventral hippocampus (see Table 2).

Histological analysis of the medial entorhinal cortex lesions (Fig. 3) included prominent damage to the medial entorhinal cortex (a range of $75 \%-100 \%$ ), parasubiculum, and presubiculum as well as some ventral hippocampal and subiculum damage, but no damage to the anterior or posterior perirhinal cortex (see Table 3).

\section{Continuous Recognition Memory}

The mean number of acquisition sessions required for each of the surgical groups ranged between 47.4 and 65.8. The mean number of training sessions was 65.8 for the control group, $\mathbf{4 7 . 4}$ for the perirhinal cortex group, 52.5 for the lateral entorhinal cortex group, and 49.2 for the medial entorhinal cortex group. The groups did not differ significantly from each other in the number of trials to acquisition.

The data for the last block of 16 sessions before surgery and the first and second block of 16 sessions after surgery, with 12 observations per lag, are shown in Figure 4 for each of the lesion groups. Mean difference scores were derived by subtracting the latency to move an object on the first presentation (go condition) from the latency on the second presentation of the same object (no go condition). A large difference score resulted when the rat moved the object slower on a repeated presentation, or when the rat did not move the object at all for $10 \mathrm{sec}$ (the time limit) and indicated recognition of the object as well as knowledge of the rule (repeated presentations do not contain food). To assess the reliability of the latency scores, we had five raters score one series of videotaped recordings of one session with four different animals. The within-session reliability was $r=0.99$. Figure 4 indicates that the only lesion group that showed a sustained postsurgical deficit was the group with perirhinal cortex lesions.

With respect to baseline responding in nonrepeat visual object trials (go trials), the controls and perirhinal-, lateral entorhinal-, and medial entorhinal cortexlesioned rats exhibited similar latencies in displacing the object. During the presurgery condition, the mean latency in the control and perirhinal, lateral entorhinal, and medial entorhinal cortex groups was 2.05, $1.87,2.41$, and $2.23 \mathrm{sec}$, respectively. For the first postsurgery condition, the mean latency for the go trials was $2.10 \mathrm{sec}$ for controls and $1.47 \mathrm{sec}$ for the perirhinal-, $2.03 \mathrm{sec}$ for the lateral entorhinal-, and $2.48 \mathrm{sec}$ for the medial entorhinal cortex-lesioned groups. For the second postsurgery condition, the mean latency for the go trials was $2.17 \mathrm{sec}$ for controls

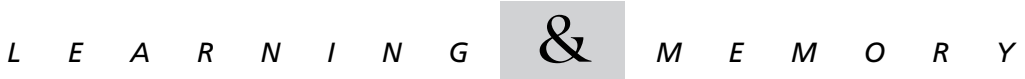


Table II. Performance Index Data for Rats with Lateral Entorhinal Cortex Lesions

\begin{tabular}{lccc}
\hline $\begin{array}{l}\text { Percent damage } \\
\text { to lateral } \\
\text { entorirhinal } \\
\text { cortex }\end{array}$ & $\begin{array}{c}\text { Percent damage } \\
\text { to anterior } \\
\text { perirhinal cortex }\end{array}$ & $\begin{array}{c}\text { Percent } \\
\text { damage to } \\
\text { postrhinal } \\
\text { cortex }\end{array}$ & $\begin{array}{c}\text { Performance } \\
\text { index* }\end{array}$ \\
\hline 74.2 & 0 & 67.8 & .466 \\
82.2 & 0 & 58.7 & .383 \\
53.3 & 0 & 57.0 & .295 \\
66.4 & 0 & 32.5 & .109 \\
\hline
\end{tabular}

Percentage damage to entorirhinal cortex, anterior perirhinal cortex, and posterior perirhinal cortex (postrhinal cortex), and performance on the continuous-recognition memory task for rats with lateral entorhinal cortex lesions.

*The higher the score, the worse the performance.

and $1.30 \mathrm{sec}$ for the perirhinal-, $1.69 \mathrm{sec}$ for the lateral entorhinal-, and $1.84 \mathrm{sec}$ for the medial entorhinal cortexlesioned groups. The groups did not differ significantly from each other in the latency to displace an object during go trials for either the pre- or postsurgery conditions.

A three-way group by pre- vs. postsurgery by lag repeated measures ANOVA was then performed. The analysis revealed a significant effect of pre- vs. postsurgery $(F[2,46]=4.59, P<0.015)$, a group by pre- vs. postsurgery interaction that reaches significance $(F[6,46]=1.95$, $P<0.09)$, a significant effect of lag $(F[4,92]=59.6, P<$ 0.0001 ), and a significant lag by pre- vs. postsurgery interaction $(F[8,184]=2.42, P<0.017)$. Further analysis of the group by pre- and postsurgery interaction using a Duncan range paired comparison test revealed that there were no significant differences among the three groups presurgically. Furthermore, in the first and second postsurgical tests, the perirhinal cortex-lesioned group performed significantly different than it had on its presurgical tests $(P<0.05)$ and significantly different from the postsurgical performance of the control group $(P<0.05)$, whereas the lateral entorhinal cortex- or medial entorhinal cortex-lesioned group did not perform significantly different than it had on its presurgical test or significantly different from the postsurgical performance of the control group. Finally, Duncan range tests on the lag effect revealed that the 0 and 1 lag were significantly different from the 2,3 , and 4 lags $(P<0.05)$, suggesting that overall there was a reliable forgetting function across lag.

A separate repeated measures ANOVA with control and perirhinal groups as the between factor and pre- and postsurgical sessions and lag as the within factors revealed a significant pre- and postsurgery effect $(F[\mathrm{df} 2,34]=7.02$, $P<0.0028)$, a significant lag effect $(F[\mathrm{df} 4,68]=42.1$, $P<0.0001)$, and a significant interaction between lesion group and pre- and postsurgery $(F<$ df 2,34$]=5.95$, $P<0.0061$ ). A further analysis (Duncan range) of the group by pre-postsurgery interaction effect revealed that for the control group, there were no significant pre- vs. postsurgery effects, but for the perirhinal group, performance was impaired for the first and second postsurgery condition compared with that of the presurgery condition $(P<0.01)$. The perirhinal cortex-lesioned group performed significantly different from the control group for the first and second second postsurgery test $(P<0.05)$. Histological analysis revealed that half the subjects in the perirhinal cortex group had some TE2 damage. On the basis of $t$ tests, the subjects with or without TE2 damage did not differ significantly from each other. Similarly, added damage to the parietal cortex did not exacerbate the perirhinal cortex impairment. A correlation between a ratio measure of performance that takes into account presurgery-level performance (the average across lags presurgery latency difference minus the average across lags postsurgery latency difference divided by the presurgery score) and percentage of damage to the postrhinal cortex resulted in $r=0.50, P<0.2$, which, however, did not reach significance (see Table 1). A correlation between behavioral performance and percentage of damage to the anterior perirhinal cortex resulted in $r=0.15, P<0.7$, which clearly was not significant. Dividing the perirhinal cortex-lesioned subjects into small and large postrhinal cortex-lesioned groups did not result in a significant postrhinal cortex lesion effect.

\section{Successive Discrimination}

On the basis of the criterion of reaching at least a 4-sec latency difference between the positive and negative stimulus and at least a 6-sec latency to respond to the negative stimulus on three consecutive days of 10 trial blocks, the control group averaged 223 trials and the perirhinal group averaged 210 trials. The difference between the two groups was not significant. Clearly, the perirhinal cortex-lesioned groups learned the successive discrimination as well as the controls had, and the perirhinal-lesioned animals were able to inhibit responding to the negative stimulus.

\section{DISCUSSION}

The results indicate that the perirhinal cortex lesions produced a profound impairment in continuous recognition memory for object information. These data are consistent with the results of Aggleton et al. (1997), Barnes et al. (2000), Ennaceur et al. (1996), and Mumby and Pinel (1994), who described similar deficits in rats by using somewhat different procedures to assess recognition memory for object information. The results are also consistent with the findings of perirhinal cortex-induced recognition memory deficits in monkeys (Gaffan and Murray 1992; Meunier et al. 1993; Suzuki et al. 1993; Buffalo et al. 1999). The deficits cannot be the result of perceptual problems in that the perirhinal cortex-lesioned animals had no difficulty acquiring a successive object discrimination. The deficits also can-

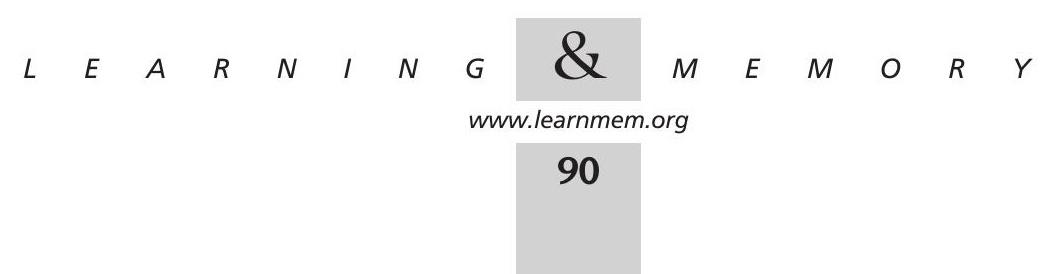



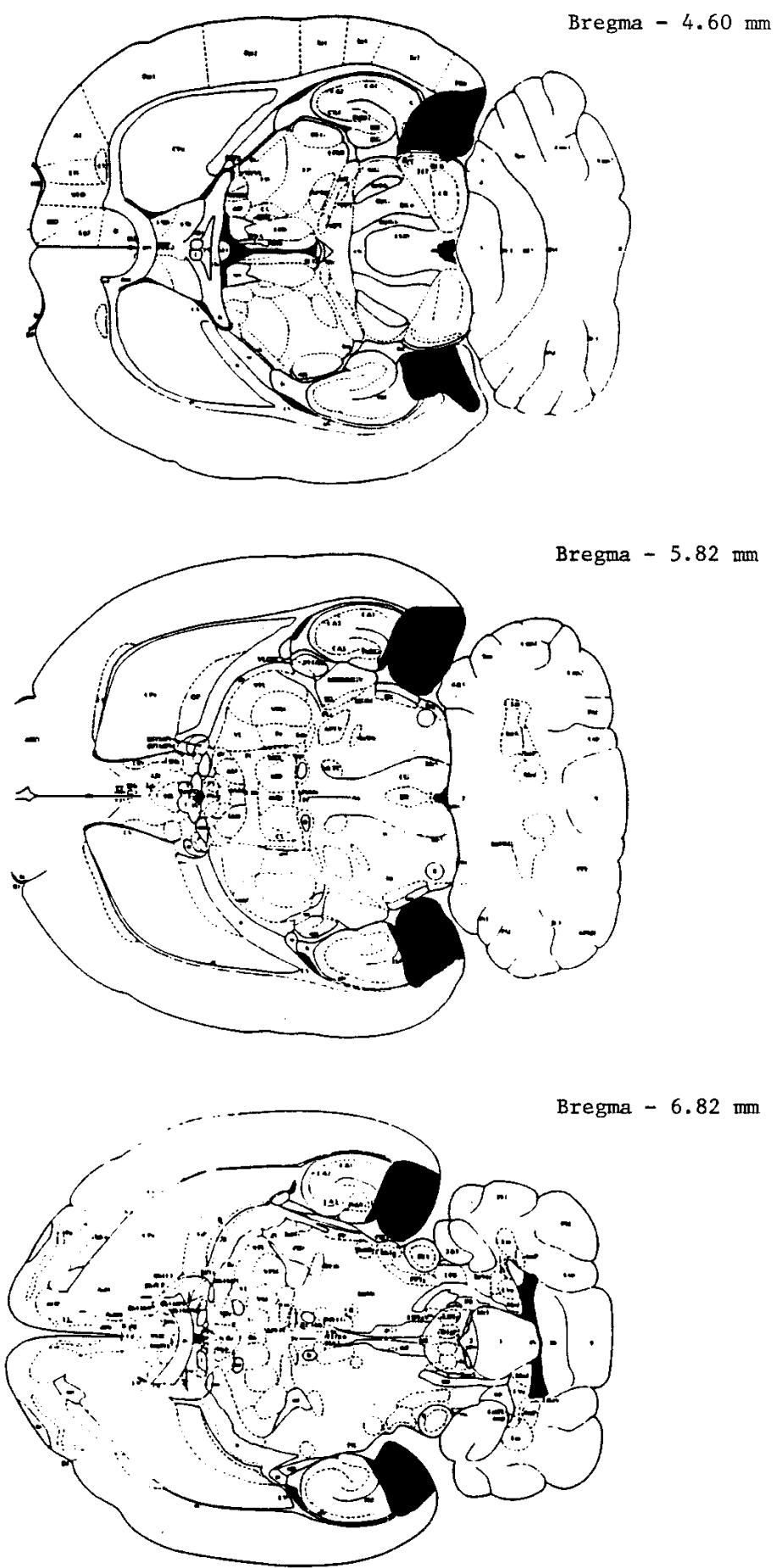

Figure 3 A schematic drawing of a representative lesion of the medial entorhinal cortex. Rat brain sections were taken from Paxinos and Watson (1986).

not be due to a problem with response inhibition, given that the lesioned rats displayed excellent inhibition in the successive object discrimination task. The same pattern of intact visual discrimination with impaired visual object rec- ognition has been reported for both rats and monkeys (Aggleton et al. 1997; Buckley et al. 1997). The results are also consistent with the observation that single cells in the perirhinal cortex respond differentially to familiar versus novel stimuli in rats and monkeys, even though the animals were not required to remember the repetition (Zhu et al. 1995; Brown 1996).

In the present study, there were no deficits after medial entorhinal cortex lesions, suggesting that perhaps the medial entorhinal cortex does not participate in short-term or working memory for visual object information. In contrast, for the lateral entorhinal cortex-lesioned group, there appeared to be some reduction in performance on the first postsurgery session relative to the presurgery session and relative to the first postsurgery session of the control group. Although not statistically significant, this could have been the result of small damage to the perirhinal cortex. Furthermore, there was almost complete recovery of function on the second postsurgery session. This lack of a permanent deficit after lateral entorhinal cortex lesions is consistent with a similar lack of effect using a nonmatching-to-sample task for visual object information in monkeys (Leonard et al. 1995). There is, however, a possibility that the medial and lateral entorhinal cortex operate together in contributing to short-term or working memory for visual object information. Other data suggest that the entorhinal cortex is very important for spatial and odor short-term memory (Barnes 1988; Otto and Eichenbaum 1992; Hunt et al. 1994; Liu and Bilkey 1998).

With respect to the neural circuit that might support visual object recognition in the rat, two additional neural regions, namely, the medial extrastriate cortex and the pre- and infralimbic cortex, which have reciprocal connections with the perirhinal cortex (Burwell et al. 1995; Conde et al. 1995; Witter et al. 1989), have thus far been identified. In different studies it has been shown that the medial extrastriate visual cortex or pre- and infralimbic cortex lesions in the rat impair short-term memory for visual object information, suggesting that these neural regions may be part of a neural circuit that mediates memory for visual object information and thus play an important role in visual object recognition memory (Kesner et al. 1993, 1996).

In summary, using a continuous recognition memory procedure to measure short-term memory for visual objects, it has been shown that the perirhinal cortex, but not medial entorhinal and lateral entorhinal cortex, plays an important role in supporting short-term memory for visual object information in the rat. These findings parallel similar results obtained with perirrhinal or entorhinal cortex lesions in monkeys.

$$
\begin{array}{lllllllllllllll} 
& E & A & R & N & I & N & G & \mathbf{Q} & M & E & M & O & R & Y \\
\text { www.learnmem.org } & & &
\end{array}
$$


Table III. Performance Index Data for Rats with Medial Entorhinal Cortex Lesions

\begin{tabular}{rccc}
\hline $\begin{array}{l}\text { Percent damage } \\
\text { to medial } \\
\text { entorhinal } \\
\text { cortex }\end{array}$ & $\begin{array}{c}\text { Percent damage } \\
\text { to anterior } \\
\text { perirhinal cortex }\end{array}$ & $\begin{array}{c}\text { Percent } \\
\text { damage to } \\
\text { postrhinal } \\
\text { cortex }\end{array}$ & $\begin{array}{c}\text { Performance } \\
\text { index* }\end{array}$ \\
\hline 75 & 0 & 0 & .130 \\
100 & 0 & 0 & .166 \\
100 & 0 & 0 & .385 \\
100 & 0 & 0 & -.078 \\
\hline
\end{tabular}

Percent damage to perirhinal cortex, anterior perirhinal cortex, and posterior perirhinal cortex (postrhinal cortex) and performance on the continuous recognition memory task for rats with medial entorhinal cortex lesions.

*The higher the score, the worse the performance.

\section{MATERIALS AND METHODS}

\section{Subjects}

The subjects were 27 male Long-Evans rats, weighing between 275 and $325 \mathrm{~g}$. The rats were initially deprived to and maintained at $80 \%$ of their ad lib weight and allowed continuous access to water in their home cage; thereafter, their weights were increased by $\sim 5 \%$ every 4-6 weeks. Each rat was housed individually in a laboratory with a 14-h-light/10-h-dark cycle, and all testing occurred during the light cycle.

\section{Apparatus}

The apparatus consisted of a table that was $122.0 \mathrm{~cm}$ long by 35.5 $\mathrm{cm}$ wide, with a black Plexiglas door $(50.5 \mathrm{~cm}$ tall by $43.0 \mathrm{~cm}$ wide) separating the table into two sides. The table was constructed of painted black wood and was raised $91.0 \mathrm{~cm}$ above the floor. Each side contained three 2.6-cm-diameter food wells, separated by 6.0 $\mathrm{cm}$, located $5 \mathrm{~cm}$ from the back edge, and centered from side to side. A sheet of red Plexiglas $(88.0 \mathrm{~cm}$ tall by $91.0 \mathrm{~cm}$ wide) $\mathrm{ex}-$

C LATERAL ENTORHINAL CORTEX
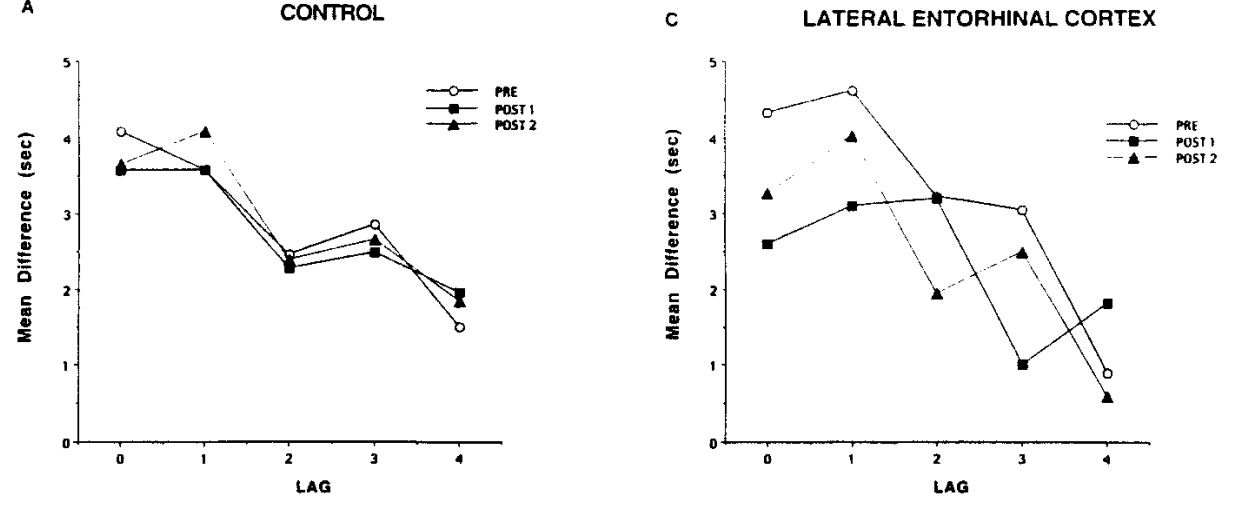

B PERIRHINAL CORTEX

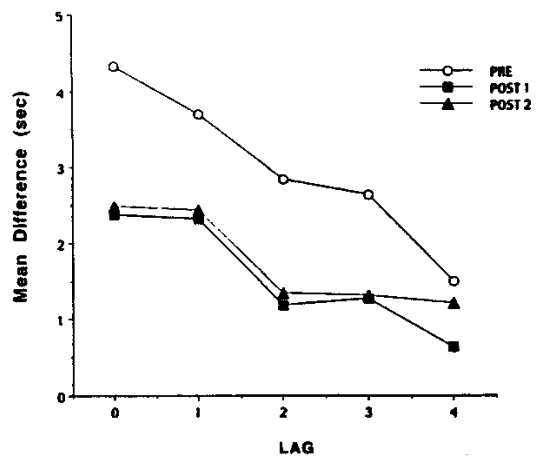

D

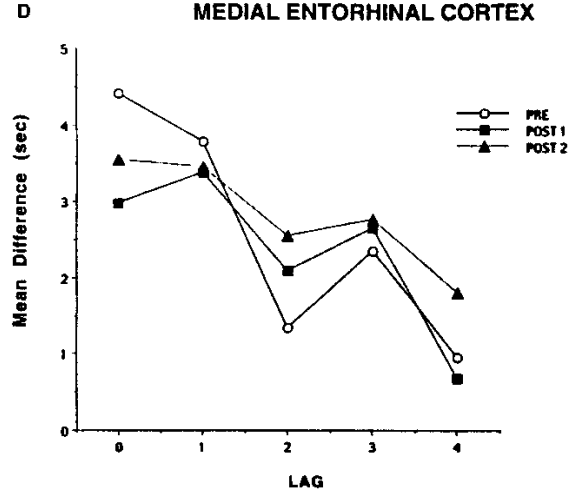

Figure 4 Mean difference in latency to move an object on first versus repeated presentations of the same object as a function of lag (number of different objects presented between the first and second presentation) for the last block of 16 sessions before surgery (PRE) and the two blocks of 16 sessions after surgery (POST1, POST2) for rats with sham control lesions $(A)$, perirhinal cortex lesions $(B)$, lateral entorhinal cortex lesions $(C)$, and medial entorhinal cortex lesions $(D)$.




tended across one side of the table to block the animals' view of the experimenter and the room, and the opposite side of the table was against the wall. The table was located in a small room with one door, one worktable, and bookshelves containing the stimulus objects. The stimuli for this experiment were three-dimensional objects in various shapes, sizes, textures, and brightness. There were 120 stimuli in all, composed primarily of small toys and junk objects.

\section{Continuous Recognition Memory}

The methods used were adapted from Jackson-Smith et al. (1993). As in that study, the rats were habituated to the table with the door raised for 2 days. Pretraining then consisted of placing the rat at one end of the table with the door closed, raising the door, and allowing the rat to approach and move an object placed on the center food well with a whole piece of Froot Loop cereal underneath it. Once the animal was on the same side of the table as the stimulus, the door was lowered, and the next stimulus was set up on the other side of the table. When the rat had finished eating the Froot Loop cereal reinforcement, the stimulus associated with that reinforcement was removed from the table and an intertrial interval (ITI) of $10 \mathrm{sec}$ elapsed. At the end of the ITI, the door was rattled to attract the rat's attention, and when the rat moved to the door, it was opened. During early pretraining, the object only partially covered the food well, but as the rat learned to move the stimulus and look for reinforcement under it, the object was gradually placed completely over the food well. The stimuli used in pretraining were not in the set of 120 objects used for the task, and there was a maximum of four reinforced trials per day. The total number of pretraining sessions ranged from 8 to 12 .

The training procedure was similar to the procedure used in pretraining: the rat was placed on the right side of the table; one stimulus was placed on the center food well on the left side of the table with one-half of a piece of Froot Loop cereal under it; a ready signal was given (rattling the door); and as soon as the rat had oriented to the door, it was raised. The amount of time that elapsed between opening the door and moving the object was measured. If the rat did not move the object within $10 \mathrm{sec}$ on a repeated-stimulus trial, the object was removed and the ITI began. The door was lowered as soon as the rat had moved to the opposite side, and when the rat had finished eating the cereal, or $\sim 6 \mathrm{sec}$ after the object had been moved on nonreinforced trials, the stimulus object was removed from the table. An ITI of $10 \mathrm{sec}$ occurred once the object had been removed, and the next trial was as described except that the stimulus was placed on the opposite side of the table. Placement of the objects alternated from side to side on the table as the trials progressed, but the number of repeated stimulus presentations per side was counterbalanced across a block of 16 sessions. If an object had been presented previously during the current session, the second presentation did not contain reinforcement. The maximum time allowed to move the stimulus on repeated object trials was $10 \mathrm{sec}$, but a session was terminated if a rat did not move an object and eat the reinforcement within 3 min on nonrepeated trials.

All rats ran one session per day, five days a week. Each session involved sequential presentation of eight unique objects, and four repeated objects (chosen from the eight). For every object there were two identical copies, so that a new copy was presented during a repetition to avoid the potential use of odor cues. Repeated objects had lags ranging from 0 to 4 . For each session within a block of 16 sessions, eight new objects were randomly chosen from the set of 120 and quasirandomly presented. No object was presented within five sessions of itself, and each object served as a repeated presentation once every 30 sessions. A different lag was assigned an object each time it served as a repeated stimulus. Each block of 16 sessions contained 12 trials at each of the five lags. If rats demonstrated significantly longer latencies to move the object on repeated trials than on nonrepeated trials using a $t$ test at the zero lag, and at least one other lag, for the last block of 16 sessions, then surgery was performed. All rats were allowed 7-10 days to recover from surgery, after which they were retested for two blocks of 16 sessions

\section{Surgery}

Surgery was performed under aseptic conditions. Rats were given atropine sulfate $(0.2 \mathrm{mg} / \mathrm{kg}$ ip) as a prophylactic and anesthetized with Nembutal ( $50 \mathrm{mg} / \mathrm{kg}$ ip sodium pentobarbital) before surgery. Animals in all four groups were incised along the midline, and the periosteal fascia was scraped to the side. The control group $(n=11)$ was then sutured and placed on a heating pad to recover. For the medial entorhinal cortex $(n=4)$ and lateral entorhinal cortex $(n=4)$ lesion groups, the bone dorsal to the entorhinal cortex was removed by a dental burr. The lesion groups then received bilateral electrolytic lesions with a stainless steel electrode $(0.35$ $\mathrm{mm}$ in diameter) insulated with Epoxylite except for $\sim 0.50$ to 0.75 $\mathrm{mm}$ at the tip. The two lesion coordinates for the medial entorhinal cortex lesion, with the head level, were $6.8 \mathrm{~mm}$ posterior to bregma, $4.5 \mathrm{~mm}$ lateral to midline, $5.0 \mathrm{~mm}$ below dura, and $7.9 \mathrm{~mm}$ posterior to bregma, $4.5 \mathrm{~mm}$ lateral to midline, $5.0 \mathrm{~mm}$ below dura. For the medial entorhinal cortex lesions, the more anterior placement was lesioned with a $1.0 \mathrm{~m} \AA$ anodal current for $15 \mathrm{sec}$, and the more posterior placement was lesioned with a $1.2 \mathrm{~mA}$ anodal current for $15 \mathrm{sec}$. The two lesion coordinates for the lateral entorhinal cortex lesion, with the head level, were $7.9 \mathrm{~mm}$ posterior to bregma, $6.7 \mathrm{~mm}$ lateral to midline, $4.5 \mathrm{~mm}$ below dura, and $6.3 \mathrm{~mm}$ posterior to bregma, $6.2 \mathrm{~mm}$ lateral to midline, $6.0 \mathrm{~mm}$ below dura. For the lateral entorhinal cortex lesions, the more posterior placement was lesioned with a $1.2 \mathrm{~mA}$ anodal current for $9 \mathrm{sec}$, and the more anterior placement was lesioned with a $1.2 \mathrm{~mA}$ anodal current for $12 \mathrm{sec}$. For the perirhinal cortex group $(n=8)$, the bone overlying the rhinal sulcus was removed, and the perirhinal cortex (posterior bregma 8.0 to posterior bregma 3.5) was removed using aspiration.

\section{Successive Discrimination}

After completion of 32 sessions of the continuous recognition memory task following surgery, animals within the control and perirhinal lesion groups were tested for the acquisition of a successive object discrimination task. This discrimination task was designed to assess whether possible lesion effects on the continuous recognition task could be the result of a perceptual problem in processing visual object information or the result of an inability to withhold responding. In this task, one novel toy object was designated as positive and resulted in reinforcement of a half a piece of Froot Loop, whereas the other novel toy object was designated as negative and did not result in reinforcement. The reinforcementnonreinforcement contingencies were counterbalanced across subjects. The training procedure was similar to the procedure used in the continuous recognition memory task. The rat was placed on the right side of the table, one stimulus was placed on the center food well on the left side of the table with one-half of a piece of Froot Loop cereal under it, a ready signal was given (rattling the door),




and as soon as the rat had oriented to the door, it was raised. The amount of time that elapsed between the opening of the door and the moving of the object was measured. If the rat did not move the object within $10 \mathrm{sec}$ on a nonreinforced trial, the object was removed and the ITI began. The door was lowered as soon as the rat had moved to the opposite side, and when the rat had finished eating the cereal, or $\sim 6 \mathrm{sec}$ after the object had been moved on nonreinforced trials, the stimulus object was removed from the table. An ITI of $10 \mathrm{sec}$ occurred once the object had been removed, and the next trial was as described except that the stimulus was placed on the opposite side of the table. Placement of the objects alternated from side to side on the table as the trials progressed. Each rat received 10 trials/d (five positive and five negative) for $30 \mathrm{~d}$.

\section{Histology}

At the end of all testing, the lesioned animals were deeply anesthetized with 1 or $1.5 \mathrm{~mL}$ of sodium pentobarbital and perfused with $10 \%$ formalin in isotonic saline. The brains were frozen and cut horizontally using 24-micron sections through the region of the entorhinal cortex or cut coronally through the perirhinal cortex. Every fourth section was mounted on glass slides and stained with cresyl violet to examine the extent of the lesion.

\section{ACKNOWLEDGMENTS}

This research was supported by National Science Foundation Grant BNS 892-1532.

The publication costs of this article were defrayed in part by payment of page charges. This article must therefore be hereby marked "advertisement" in accordance with 18 USC section 1734 solely to indicate this fact.

\section{REFERENCES}

Aggleton, J.P., Keen, S., Warburton, E.C., and Bussey, T.J. 1997. Extensive cytotoxic lesions involving both the rhinal cortices and area TE impair recognition but spare spatial alternation in the rat. Brain Res. Bull. 43: $279-287$.

Barnes, S.J., Floresco, S.B., Kornecook, T.J., and Pinel, J.P.J. 2000. Reversible lesions of the rhinal cortex produce delayed non-matching-to-sample deficits in rats. NeuroReport 11: 351-354

Brown, M.W. 1996. Neuronal responses and recognition memory. Semin. Neurosci. 8: 23-32.

Buckley, M.J., Gaffan, D., and Murray. E.A. 1997. Functional double dissociation between two inferior temporal cortical areas: Perirhinal cortex versus middle temporal gyrus. J. Neurophysiol. 77: 587-598.

Buffalo, E.A., Ramus, S.J., Clark, R.E., Teng, E., Squire, L.R., and Zola, S.M. 1999. Dissociation between the effects of damage to perirhinal cortex and area TE. Learn. Mem. 6: 572-599.

Burwell, R.D., Witter, M.P., and Amaral, D.G. 1995. Perirhinal and postrhinal cortices of the rat: A review of the neuroanatomical literature and comparison with findings from the monkey brain. Hippocampus 5: 390-408.

Conde, F., Maire-Lepoivre, E., Audinat, E., and Crepel, F. 1995. Afferent connections of the medial frontal cortex of the rat. II. Cortical and subcortical afferents. J. Comp. Neurol. 352: 567-593.

Coogan, T.A. and Burkhalter, A. 1990. Conserved patterns of corticocortical connections define areal hierarchy in rat visual cortex. Exp. Brain Res. 80: 49-53.

Davis, B.K. and McDaniel, W.F. 1993. Visual memory and visual spatial functions in the rat following parietal and temporal cortex injuries. Physiol. Behav. 53: 145-151.

Deacon, T.W., Eichenbaum, H., Rosenberg, P., and Eckmann, K.W. 1983. Afferent connections of the perirhinal cortex in the rat. J. Comp. Neurol. 220: 168-190.
Eacott, M.J., Gaffan, D., and Murray, E.A. 1994. Preserved recognition memory for small sets, and impaired stimulus identification for large sets, following rhinal cortex ablations in monkeys. Eur. J. Neurosci. 6: $1466-1478$.

Ennaceur, A., Neave, N., and Aggleton, J.P. 1996. Neurotoxic lesions of the perirhinal cortex do not mimic the behavioral effects of fornix transection in the rat. Behav. Brain Res. 80: 9-26.

Gaffan, D. 1994. Dissociated effects of perirhinal cortex ablation, fornix transection and amygdalectomy: Evidence for multiple memory systems in the primate temporal lobe. Exp. Brain Res. 99: 411-422.

Gaffan, D. and Murray, E.A. 1992. Monkeys (Macaca fasicularis) with rhinal cortex ablations succeed in object discrimination learning despite 24-Hr intertrial intervals and fail at matching to sample despite double sample presentations. Behav. Neurosci. 106: 30-38.

Horel, J.A., Pytko-Joiner, D.E., Boytko, M.L., and Salsbury, K. 1987. The performance of visual tasks while segments of the inferotemporal cortex are suppressed by cold. Behav. Brain Res. 23: 29-42.

Hunt, M.E., Kesner, R.P., and Evans, R.B. 1994. Memory for spatial location: Functional dissociation of entorhinal cortex and hippocampus. Psychobiology 22: 186-194.

Jackson-Smith, P., Kesner, R.P., and Chiba, A.A. 1993. Continuous recognition of spatial and nonspatial stimuli in hippocampal-lesioned rats. Behav. Neural Biol. 59: 107-119.

Kesner, R.P. and Giles, R. 1998. Neural circuit analysis of spatial working memory: Role of pre- and parasubiculum, medial and lateral entorhinal cortex. Hippocampus 8: 416-423.

Kesner, R.P., Bolland, B.L., and Dakis, M. 1993. Memory for spatial locations, motor responses, and objects: Triple dissociation among the hippocampus, caudate nucleus, and extrastriate visual cortex. Exp. Brain Res. 93: 462-470.

Kesner, R.P., Hunt, M.E., Williams, J.M., and Long, J.M. 1996. Prefrontal cortex and working memory for spatial response, spatial location, and visual object information in the rat. Cereb. Cortex 6: 311-318

Kolb, B., Buhrmann, K., McDonald, R., and Sutherland, R.J. 1994 Dissociation of the medial prefrontal, posterior parietal, and posterior temporal cortex for spatial navigation and recognition memory in the rat. Cereb. Cortex 6: 664-680.

Leonard, B.W., Amaral, D.G., Squire, L.R., and Zola-Morgan, S. 1995. Transient memory impairment in monkeys with bilateral lesions of the entorhinal cortex. J. Neurosci. 15: 5637-5659.

Liu, P. and Bilkey, D.K. 1998. Excitoxic lesions centered on perirhinal cortex produce delay-dependent deficits in a test of spatial memory Behav. Neurosci. 112: 512-524.

Martin-Elkins, C.L., George, P., and Horel, J.A. 1989. Retention deficits produced in monkeys with reversible cold lesions in the prestriate cortex. Behav. Brain Res. 32: 219-230.

Meunier, M., Bachevalier, J., Mishkin, M., and Murray, E.A. 1993. Effects on visual recognition of combined and separate ablations of the entorhinal and perirhinal cortex in rhesus monkeys. J. Neurosci. 13: 5418-5432.

Miller, M.W. and Vogt, B.A. 1984. Direct connections of rat visual cortex with sensory, motor, and association cortex. J. Comp. Neurol. 226: $184-202$

Mumby, D.G. and Pinel, J.P.J. 1994. Rhinal cortex lesions and object recognition in rats. Behav. Neurosci. 108: 11-18

Otto, T. and Eichenbaum, H. 1992. Complementary roles of the orbital prefrontal cortex and the perirhinal-entorhinal cortices in an odor-guided delayed-nonmatching-to-sample task. Behav. Neurosci. 106: $762-775$

Paxinos, G. and Watson, C. 1986. The rat brain in stereotaxic coordinates, 2nd ed. Academic Press, Sydney, Australia

Sanderson, K.J., Dreher, B., and Gayer, N. 1991. Prosencephalic connections of striate and extrastriate areas of rat visual cortex. Exp. Brain Res. 85: 324-334.

Suzuki, W.A., Zola-Morgan, S., Squire, L.R., and Amaral, D.G. 1993. Lesions of the perirhinal and parahippocampal cortices in the monkey

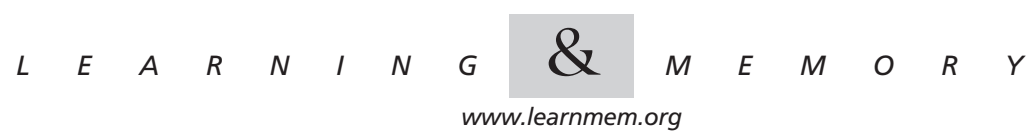


produce long lasting memory impairment in the visual and tactual modalities. J. Neurosci. 13: 2430-2451.

Ungerleider, L.G. and Mishkin, M. 1982. Two cortical visual systems. In Analysis of visual behavior (eds. D.J. Ingle, M.A. Goodale, and R.J.W. Mansfield), pp. 549-586. MIT Press, Cambridge, MA.

Vaudana, E., Legg, C.R., and Glickstein, M. 1991. Afferent and efferent connections of temporal association cortex in the rat: A horseradish peroxidase study. Eur. J. Neurosci. 3: 317-330.

Witter, M.P., Groenewegen, H.J., Lopes da Silva, F.H., and Lohman, A.H.M 1989. Functional orgnization of the extrinsic and intrinsic circuitry of the parahippocampal region. Prog. Neurobiol. 33: 161-253.
Zhu, X.O., Brown, M.W., and Aggleton, J.P. 1995. Neuronal signalling of information important to visual recognition memory in rat rhinal and neighbouring cortices. Eur. J. Neurosci. 7: 753-765.

Zola-Morgan, S., Squire, L.R., Amaral, D.G., and Suzuki, W.A. 1989. Lesions of perirhinal and parahippocampal cortex that spare the amygdala and hippocampal formation produce severe memory impairment. $J$.

Neurosci. 9: 4355-4370.

Received September 28, 1999; accepted in revised form February 8, 2001. 




\section{A Neural Circuit Analysis of Visual Recognition Memory: Role of Perirhinal, Medial, and Lateral Entorhinal Cortex}

Raymond P. Kesner, Ajay Ravindranathan, Pamela Jackson, et al.

Learn. Mem. 2001, 8:

Access the most recent version at doi:10.1101/lm.29401

References This article cites 33 articles, 5 of which can be accessed free at: http://learnmem.cshlp.org/content/8/2/87.full.html\#ref-list-1

License

Email Alerting Receive free email alerts when new articles cite this article - sign up in the box at the Service top right corner of the article or click here. 